\title{
Microsatellite variation in solitary and social tuco-tucos: molecular properties and population dynamics
}

\author{
EILEEN A. LACEY \\ Museum of Vertebrate Zoology, Department of Integrative Biology, University of California, Berkeley \\ CA 94720 U.S.A.
}

\begin{abstract}
Variation at 15 microsatellite loci was characterized for a population of the solitary Patagonian tucotuco (Ctenomys haigi) and a population of group-living colonial tuco-tuco (C. sociabilis), both of which were located in the Limay River Valley of south western Argentina. All loci examined were characterized by uninterrupted di- or trinucleotide repeats in both species; seven of these loci had been isolated from $C$. haigi and eight had been isolated from $C$. sociabilis. Across all loci, there was a significant tendency for both number of alleles and heterozygosity to be greater in $C$. haigi than in C. sociabilis. Cloning and sequencing of multiple PCR products per locus per population revealed no significant biases in allele length, suggesting that this difference in variability was not due to ascertainment bias or to population-wide differences in rates of microsatellite evolution. Instead, differences in microsatellite variation between $C$. haigi and $C$. sociabilis were more consistent with current demographic and suspected historical differences between these populations. In particular, interpopulation differences in the distribution of microsatellite allele sizes and allele frequencies suggested that $C$. sociabilis has been more subject to historical reductions in population size (e.g. population bottlenecks) than has $C$. haigi. These findings indicate that analyses of microsatellite structure can yield important insights into the population-level phenomena that contribute to diversity at these markers, including differences in population history that continue to influence levels of genetic variability.
\end{abstract}

Keywords: Ctenomys, microsatellites, tuco-tucos, population bottleneck, variability.

\section{Introduction}

A fundamental goal of molecular studies of population structure is to determine how current and historical processes interact to shape patterns of genetic differentiation (Avise, 1994; p. 232). Comparative studies of closely related species that differ with respect to only one or a few key population parameters provide a potentially powerful means of achieving this objective. Interspecific differences in genetic structure, however, may arise due to molecular-level differences among the taxa sampled as well as the population-level processes of interest. For example, as use of microsatellites to characterize population-level variability has increased, concerns have arisen regarding several aspects of microsatellite structure and evolution that may confound comparisons of genetic variation. These include differences in repeat motif (Estoup et al., 1995; van

Correspondence. E-mail: ealacey@socrates.berkeley.edu
Treuren et al., 1997), biases in allele lengths (Ellegren et al., 1995), and changes in flanking-region sequences that produce non-amplifying alleles (Ishibashi et al., 1996), each of which has been shown to influence levels of genetic variation detected at microsatellite loci. As a result, consideration of the molecular-level characteristics of the species sampled represents a critical component of comparative studies of genetic population structure.

As part of ongoing studies of the population biology of ctenomyid rodents, I examined patterns of microsatellite variation in the colonial tuco-tuco (Ctenomys sociabilis) and the Patagonian tuco-tuco ( $C$. haigi). Although phylogenetic analyses based on sequence data from the cytochrome $b$ region of the mitochondrial genome indicate that these species are not sister taxa (Lacey and Smith, in prep., but see also Lessa \& Cook, 1998), both occur in the Limay River Valley in southwestern Argentina, where populations of heterospecifics are separated only by the width of the Río Limay 
$(\approx 500 \mathrm{~m})$. Despite their close physical proximity and their use of similar habitats, these animals exhibit striking differences in behaviour and demography. C. haigi is solitary, meaning that burrow systems of this species are never inhabited by more than a single adult (Lacey et al., 1998). In contrast, burrow systems of C. sociabilis are routinely inhabited by multiple adult females and, in some cases, an adult male (Lacey et al., 1997). Although more than 30 species of tuco-tucos are currently recognized (Woods, 1993), C. sociabilis is the only ctenomyid for which quantitative evidence of group living has been obtained and thus comparative studies of this species and $C$. haigi provide an apparently unique opportunity to examine the genetic consequences of interactions between behaviour demography and population history in ecologically similar tuco-tucos.

As a first step toward characterizing the genetic structures of $C$. haigi and $C$. sociabilis, I quantified microsatellite variation within one population of each species. The populations selected for analysis are the subjects of ongoing field research and thus their current behaviour and demography are well documented. Here, I report on the patterns of microsatellite variability evident in these populations and I assess the role of microsatellite structure in generating these differences. As these analyses indicate, rather than confounding comparative studies of genetic variability, the structural properties of microsatellite markers may yield important insights into the population-level processes underlying that variation.

\section{Methods}

\section{Sample collection}

The population of $C$. haigi sampled was located on Estancia San Ramon, Provincia Río Negro, Argentina $\left(40^{\circ} 56^{\prime} \mathrm{S}, 71^{\circ} 03^{\prime} \mathrm{W}\right)$. The population of $C$. sociabilis sampled was located directly across the Río Limay, on Estancia Rincon Grande, Provincia Neuquén, Argentina $\left(40^{\circ} 56^{\prime} \mathrm{S}, 71^{\circ} 03^{\prime} \mathrm{W}\right)$. During $1993-95$, non-destructive tissue samples were collected from all animals trapped in these populations by removing the distal 2-3 mm of the outer digit on the right hind foot of each individual. Tissue samples were stored in $\mathrm{DMSO}_{4}$ EDTA buffer (Seutin et al., 1991) at ambient temperature. Because burrow sharing in C. sociabilis arises due to natal philopatry by females (Lacey, 2000), individuals from the same burrow system are typically closely related and are thus likely to share a substantial portion of their genomes due to common ancestry. To avoid underestimating genetic diversity in $C$. sociabilis, samples from 35 animals resident in 14 different burrow systems $(2.6 \pm 2.5$ animals per system $)$ were chosen for analysis; the exact boundaries of these burrow systems had been determined by radiotelemetry as described in Lacey et al. (1997). In contrast, because related animals are not spatially clustered in C. haigi, samples from 35 randomly selected individuals resident throughout the study population were used to characterize microsatellite variation in this species.

\section{Microsatellite analyses}

Genetic variation at 16 microsatellite loci (later reduced to 15 loci; see results) was quantified for each study population. Eight of these loci had been isolated from C. haigi (Lacey et al., 1999). The remaining eight loci were isolated from $C$. sociabilis following the methods of Lacey et al. (1999); these loci are described in Table 1. The 16 loci used in this study were selected because (1) they produced well-resolved PCR products for both C. haigi and C. sociabilis and (2) preliminary sequencing confirmed that each locus was characterized by a simple, uninterrupted repeat in both study species. None of these loci were screened to assess variability prior to the generation of the data reported here. A total of 35 adults per species (all conspecifics from the same local population) were screened using the eight loci isolated from C. haigi; a randomly selected subset of these individuals ( $n=20$ adults per population) were characterized using the eight microsatellite loci isolated from $C$. sociabilis.

To quantify microsatellite variability in each study population, high molecular weight genomic DNA was extracted from tissue samples via digestion with proteinase $\mathrm{K}$, followed by phenol-chloroform extraction and ethanol precipitation (Sambrook et al., 1989). PCR amplification of microsatellite loci was carried out in a $15 \mu \mathrm{L}$ volume containing $30 \mathrm{ng}$ of DNA, $0.2 \mu \mathrm{M}$ each primer, $0.2 \mathrm{~mm}$ dNTP, $1 \times$ Taq buffer $\left(1.5 \mathrm{~mm} \mathrm{MgCl}_{2}\right.$, $10 \mathrm{~mm}$ Tris- $\mathrm{HCl}, 50 \mathrm{~mm} \mathrm{KCl}$ ), and 0.75 units of Taq polymerase (Boehringer Mannheim). The thermocycling regime used consisted of $94^{\circ} \mathrm{C}$ for $5 \mathrm{~min}$, followed by 34 cycles of $94^{\circ} \mathrm{C}$ for $30 \mathrm{~s}$, Ta for $30 \mathrm{~s}$, and $72^{\circ} \mathrm{C}$ for $45 \mathrm{~s}$, with a final extension of $72^{\circ} \mathrm{C}$ for $5 \mathrm{~min}$. Locus-specific annealing temperatures are given in Lacey et al. (1999) and in Table 1.

Allelic variability at each locus was examined by amplifying DNA as described above, but with one primer per pair end-labelled with $\left[\gamma^{32} \mathrm{P}\right]-\mathrm{ATP}$ via a kinase reaction (Richardson, 1965). Radioactively labelled PCR products ( $3 \mu \mathrm{L}$ per sample) were electrophoresed on $6 \%$ polyacrylamide, $40 \%$ urea denaturing sequencing gels at $1800 \mathrm{~V}$ for $2.5-6 \mathrm{~h}$, as dictated by the size of the amplification products for each locus. Radioactive gels were then exposed to Kodak XAR film for $24-72 \mathrm{~h}$ at room temperature, $-20^{\circ} \mathrm{C}$, or $-70^{\circ} \mathrm{C}$. To determine the size in base pairs of each allele 
Table 1 Characteristics of microsatellite loci isolated from Ctenomys sociabilis. $\mathrm{T}_{\mathrm{a}}$ is the annealing temperature used in PCR reactions. Repeat motifs were sequenced from cloned PCR products, as described in the text. For each locus, the repeat motif for $C$. sociabilis is listed first, followed by the repeat motif for $C$. haigi. GenBank accession numbers are indicated

\begin{tabular}{|c|c|c|c|c|}
\hline Locus & Primer sequences $\left(5^{\prime}-3^{\prime}\right)$ & $\mathrm{T}_{\mathrm{a}}\left({ }^{\circ} \mathrm{C}\right)$ & Repeat motif & Genbank accession number \\
\hline Soc 1 & $\begin{array}{l}\text { AACCTGAGGCACTGCATTCT } \\
\text { GGAAACTTTGTCCCCAGTCT }\end{array}$ & 58 & $\begin{array}{l}(\mathrm{CA})_{13} \\
(\mathrm{CA})_{15}\end{array}$ & AY007694 \\
\hline Soc 2 & $\begin{array}{l}\text { TGAGCTTCAACTTCCAGCAA } \\
\text { AGTGTGTTTCTGCCACCTCC }\end{array}$ & 58 & $\begin{array}{l}(\mathrm{CA})_{14} \\
(\mathrm{CA})_{12}\end{array}$ & AY007695 \\
\hline Soc 3 & $\begin{array}{l}\text { TGACCTACACAGTGAGACCCTG } \\
\text { GACTTATGCCCCTTTTGGCT }\end{array}$ & 60 & $\begin{array}{l}(\mathrm{CA})_{13} \\
(\mathrm{CA})_{13}\end{array}$ & AY007696 \\
\hline Soc 4 & $\begin{array}{l}\text { CCCTGCACCAAAGAAATAAAA } \\
\text { TGGGATGAGTTCTGTGTGGT }\end{array}$ & 58 & $\begin{array}{l}(\mathrm{CA})_{24} \\
(\mathrm{CA})_{15}\end{array}$ & AY007697 \\
\hline Soc 5 & $\begin{array}{l}\text { GAAGGTTGGCAATGAGCAGAT } \\
\text { TGCAGCTAAAAGGTGAAGGC }\end{array}$ & 62 & $\begin{array}{l}(\mathrm{CA})_{20} \\
(\mathrm{CA})_{25}\end{array}$ & AY007698 \\
\hline Soc 6 & $\begin{array}{l}\text { CAAGCTCTTGCCCATCACTT } \\
\text { ACTGCAGCTCAGGGGTAGTG }\end{array}$ & 62 & $\begin{array}{l}(\mathrm{CA})_{21} \\
(\mathrm{CA})_{16}\end{array}$ & AY007699 \\
\hline Soc 7 & $\begin{array}{l}\text { CCCCCACACTGAAAGCGTTAT } \\
\text { GACTGCTGGCAACTCAGGTT }\end{array}$ & 60 & $\begin{array}{l}(\mathrm{CA})_{14} \\
(\mathrm{CA})_{12}\end{array}$ & AY007700 \\
\hline Soc 8 & $\begin{array}{l}\text { TGCAGTAAGCAGAGGCTGAA } \\
\text { TTGACAGGAAGAATCTGGGG }\end{array}$ & 60 & $\begin{array}{l}(\mathrm{CA})_{19} \\
(\mathrm{CA})_{17}\end{array}$ & AY007701 \\
\hline
\end{tabular}

detected, radioactively labelled M13mp18 sequence was used as a size standard on all gels. In addition, amplicons from two to three individuals per locus were run on all gels to facilitate consistent scoring of microsatellite alleles.

To determine the number of repeat units associated with each allele, amplicons of several alleles per locus were cloned (TA Cloning Kit, Invitrogen) and three to five positive bacterial colonies from each cloning reaction were sequenced ( $\mathrm{T} 7$ promoter primer, USB) on an ABI 377 automated sequencer. For monomorphic loci, sequences from at least two individuals were compared to confirm that the number of repeat units assigned to the single allele detected was consistent. For variable loci, 2-3 alleles per locus were sequenced; the results of sequencing and radioactive screening analyses were compared to determine if size differences among alleles detected via comparison with the M13 sequence were consistent with differences in the number of repeat units assigned to distinct alleles.

\section{Data analysis}

Allelic variation at each locus was scored manually by aligning amplified fragments with the M13 size standard and the 'reference' individuals included on all gels. Genotypes were assigned to individuals based on the presence of one (homozygous) or two (heterozygous) distinct bands at each locus screened. Observed allele frequencies for each study population were calculated and were compared to values expected under HardyWeinberg conditions using ARLEQUIN 1.1 (Schneider et al., 1995). Analyses of linkage disequilibrium were also performed using ARLEQUIN 1.1. All other statistical procedures were performed using STATISTICA 5.0 (Statsoft, 1997); because several aspects of the microsatellite data (e.g. number of alleles per locus) were not normally distributed, nonparametric tests were used for most analyses. Graphical analyses of allele frequency distributions used to detect recent bottlenecks in the study populations were completed as described in Luikart et al. (1998). To quantitatively compare the likelihood of historical bottlenecks in the two study populations, estimates of $M$ (mean ratio of number of alleles to range of allele sizes) were generated according to Garza \& Williamson (2001). Throughout the text, means are reported \pm 1 standard deviation.

\section{Results}

\section{Population-level variability}

Levels of microsatellite variability differed markedly among the study populations in all three years for which samples were analysed. Although an individual's genotype was represented only once in the molecular data set, many of the animals sampled were present in the focal populations during more than one year of the study, suggesting that genotypic data from 1993, 1994 and 1995 could be pooled to yield a single, larger data 
set. The limited number of animals screened each year $(n \leq 15)$ precluded the use of standard homogeneity tests (e.g. Weir, 1990) to determine if allele frequencies differed across years. Instead, because allelic variants were identified on the basis of size variation in PCR products, mean allele sizes (in base pairs) at each locus were compared across years using one-way analyses of variance. No significant differences in mean allele sizes were detected (all $P>0.050$ ) for either population and thus data for 1993-95 were pooled for further analysis.

When each locus was considered independently, allele frequencies at two loci in the pooled data set (Soc 1 and Soc 2) deviated significantly from Hardy-Weinberg expectations in C. haigi (Table 2). When a Bonferroni correction (Rice, 1989) was applied to these analyses, however, no significant departures from Hardy-Weinberg expectations were detected (corrected $\alpha=0.0016$, $P>0.002$; Table 2). Pairwise comparisons of allele frequencies for $C$. haigi revealed significant linkage disequilibrium among two loci (Hai 2 and Hai 3; Bonferroni-corrected $\alpha=0.0004, P<0.0001)$ and thus locus Hai 2 was excluded from further consideration, reducing to 15 the number of loci used in subsequent analyses. Low levels of allelic variability in $C$. sociabilis (Table 2) precluded most pairwise assessments of linkage disequilibrium and thus I assumed that patterns of linkage in this species were the same as those in C. haigi.

All of the 15 loci included in subsequent analyses were variable in $C$. haigi. In contrast, eight $(53.3 \%)$ of these loci were monomorphic in C. sociabilis (Table 2). Of the seven loci that were variable in $C$. sociabilis, two $(28.6 \%)$ had been isolated from $C$. haigi; the remaining five $(71.4 \%)$ were isolated from $C$. sociabilis. The occurrence of variable loci in C. sociabilis was not significantly associated with the species of origin for the microsatellite regions examined (Fisher's Exact Test, two-tailed $P>0.050$ ). The number of alleles per locus detected for $C$. sociabilis ranged from one to three. In contrast, the number of alleles per locus detected for $C$. haigi ranged from three to 13 . For all loci, the number of alleles detected was greater in $C$. haigi than in C. sociabilis (Fig. 1a); this tendency was significant (Wilcoxon Signed Rank Test, $T=0.001, \quad n=15$, $P<0.001)$. Similarly, for all loci, observed heterozygosity was greater in $C$. haigi than in $C$. sociabilis (Fig. 1b); again, this tendency was significant (Wilcoxon Signed Rank Test, $T=0.001, n=15, P<0.001)$.

\section{Analyses of allele structure}

For all loci, intrapopulation differences in allele size were consistent with variation due to changes in the number of repeat units in the microsatellite region. Within each population, allele lengths always varied by multiples of the core repeat sequence ( 2 or $3 \mathrm{bp}$ ) and, at a given locus, differences among the number of repeat units in cloned alleles were consistent with the total length differences among PCR products for those alleles. Across populations, flanking sequences amplified by the same primer pair were extremely similar. For six of the loci analysed, flanking sequences for $C$. sociabilis and $C$. haigi were identical. For the remaining loci examined, insertions-deletions of 1-7 base pairs (mean $=2.7 \pm 1.7 \mathrm{bp}, \quad n=18$ indels) were evident between populations. Seven $(38.9 \%)$ of these indels were located immediately adjacent to repeat regions, with the rest scattered throughout the surrounding sequence. The mean percentage sequence divergence between $C$. sociabilis and $C$. haigi due to indels in the flanking regions of a locus was $2.7 \pm 2.6 \%$ ( $n=15$ pairs of sequences $)$.

\section{Analyses of allele size}

Within each population, there was no significant difference between the mean number of repeat units at loci isolated from $C$. haigi and those isolated from C. sociabilis (C. haigi: Mann-Whitney $U=26.0, n=7,8$, $P>0.050 ; C$. sociabilis: Mann-Whitney $U=27.5$, $n=7,8, P>0.050$ ); as a result, data from all microsatellite loci were combined for the following analyses of allele size variation. In this combined data set, there was no significant tendency for the mean number of repeat units at a locus to be greater in one study population than in the other (Wilcoxon Signed Rank $T=44.5$, $n=15, P>0.050)$. Similarly, there was no significant tendency toward a greater mean number of repeat units in either population when comparisons were restricted to loci that were monomorphic in $C$. sociabilis (Wilcoxon Signed Rank $T=14.0, n=8, P>0.050$ ). Within $C$. sociabilis, the mean number of repeat units at monomorphic loci was not significantly different from that at variable loci (Mann-Whitney $U=27.5, n=7,8$, $P>0.050$ ), indicating that the absence of multiple alleles was not due to particularly short repeat regions at monomorphic loci.

To examine patterns of allele size variation in greater detail, the mean pairwise difference in number of repeat units between alleles was determined for each locus; for simplicity, this measure is referred to as the mean size difference among alleles. Mean size differences among alleles for $C$. haigi ranged from 1.3 to 6.5 repeat units per locus; across loci, mean allele size differences for this population were normally distributed (Fig. 2; Kolmogorov-Smirnov $d=0.100, P>0.050)$. In contrast, mean allele size differences for $C$. sociabilis ranged from 0 to 9 repeat units per locus and, across loci, mean size differences appeared almost bimodal in distribution; the majority $(66.7 \%)$ of the 15 loci examined exhibited 
Table 2 Summary of microsatellite variation in Ctenomys sociabilis and C. haigi. Data are from one population per species. A total of 35 adults per species were screened for loci isolated from C. haigi (Hai 2-Hai 12); a total of 20 adults per population were screened for loci isolated from C. sociabilis (Soc 1-Soc 8). The number of alleles per locus is reported, as are the frequencies of all alleles (PCR product size for each allele reported in parentheses). Observed and expected heterozygosities are indicated, as are the results of Hardy-Weinberg analyses

\begin{tabular}{|c|c|c|c|c|c|c|}
\hline Locus & Species & $\begin{array}{l}\text { No. of } \\
\text { alleles }\end{array}$ & $\begin{array}{c}\text { Allele frequencies } \\
\text { (PCR product sizes in bp) }\end{array}$ & Ho & $\mathrm{He}$ & $\begin{array}{c}\text { Hardy-Weinberg } \\
P \text {-value } \dagger\end{array}$ \\
\hline Hai 2 & $\begin{array}{l}\text { sociabilis } \\
\text { haigi }\end{array}$ & $\begin{array}{l}1 \\
8\end{array}$ & $\begin{array}{l}1.000(132) \\
0.229(140), 0.271(146), 0.214(148), \\
0.129(152), 0.086(144), 0.026(154), \\
0.026(134), 0.014(150)\end{array}$ & $\begin{array}{l}0.000 \\
0.771\end{array}$ & $\begin{array}{l}0.000 \\
0.803\end{array}$ & $\overline{0.529}$ \\
\hline Hai 4 & $\begin{array}{l}\text { sociabilis } \\
\text { haigi }\end{array}$ & $\begin{array}{r}3 \\
13\end{array}$ & $\begin{array}{l}0.971(140), 0.014(138), 0.014(142) \\
0.243(126), 0.203(128), 0.203(132), \\
0.108(124), 0.081(138), 0.041(118), \\
0.027(134), 0.027(136), 0.014(130), \\
0.014(140), 0.014(142), 0.014(144), \\
0.014(146)\end{array}$ & $\begin{array}{l}0.057 \\
0.784\end{array}$ & $\begin{array}{l}0.057 \\
0.836\end{array}$ & $\begin{array}{l}1.000 \\
0.385\end{array}$ \\
\hline Hai 5 & $\begin{array}{l}\text { sociabilis } \\
\text { haigi }\end{array}$ & $\begin{array}{l}1 \\
6\end{array}$ & $\begin{array}{l}1.000(155) \\
0.689(159), 0.216(165), 0.054 \text { (169), } \\
0.014(161), 0.014(163), 0.014 \text { (167) }\end{array}$ & $\begin{array}{l}0.000 \\
0.459\end{array}$ & $\begin{array}{l}0.000 \\
0.473\end{array}$ & $\overline{0.200}$ \\
\hline Hai 8 & $\begin{array}{l}\text { sociabilis } \\
\text { haigi }\end{array}$ & $\begin{array}{r}1 \\
10\end{array}$ & $\begin{array}{l}1.000(95) \\
0.557(85), 0.100(107), 0.086(113), \\
0.071(99), 0.057(97), 0.029(87), \\
0.029(93), 0.029(105), 0.029(109), \\
0.014(117)\end{array}$ & $\begin{array}{l}0.000 \\
0.629\end{array}$ & $\begin{array}{l}0.000 \\
0.661\end{array}$ & $\overline{0.156}$ \\
\hline Hai 9 & $\begin{array}{l}\text { sociabilis } \\
\text { haigi }\end{array}$ & $\begin{array}{l}1 \\
3\end{array}$ & $\begin{array}{l}1.000(181) \\
0.569(173), 0.417(175), 0.014 \text { (177) }\end{array}$ & $\begin{array}{l}0.000 \\
0.528\end{array}$ & $\begin{array}{l}0.000 \\
0.502\end{array}$ & $\overline{1.000}$ \\
\hline Soc 1 & $\begin{array}{l}\text { sociabilis } \\
\text { haigi }\end{array}$ & $\begin{array}{l}2 \\
7\end{array}$ & $\begin{array}{l}0.900(217), 0.100(229) \\
0.263(229), 0.211(227), 0.184(235), \\
0.158(225), 0.079(233), 0.053(231), \\
0.053(239)\end{array}$ & $\begin{array}{l}0.200 \\
0.842\end{array}$ & $\begin{array}{l}0.190 \\
0.815\end{array}$ & $\begin{array}{l}1.000 \\
0.046\end{array}$ \\
\hline Soc 2 & $\begin{array}{l}\text { sociabilis } \\
\text { haigi }\end{array}$ & $\begin{array}{l}1 \\
9\end{array}$ & $\begin{array}{l}1.000(93) \\
0.500(107), 0.105(103), 0.079(93), \\
0.079(109), 0.052(89), 0.052(91), \\
0.052(95), 0.052(113), 0.026(111)\end{array}$ & $\begin{array}{l}0.000 \\
0.421\end{array}$ & $\begin{array}{l}0.000 \\
0.714\end{array}$ & $\overline{0.002}$ \\
\hline Soc 3 & $\begin{array}{l}\text { sociabilis } \\
\text { haigi }\end{array}$ & $\begin{array}{l}1 \\
3\end{array}$ & $\begin{array}{l}1.000(80) \\
0.763(78), 0.158(80), 0.079(92)\end{array}$ & $\begin{array}{l}0.000 \\
0.263\end{array}$ & $\begin{array}{l}0.000 \\
0.387\end{array}$ & $\overline{0.085}$ \\
\hline
\end{tabular}


Table 2 (Continued)

\begin{tabular}{|c|c|c|c|c|c|c|}
\hline Locus & Species & $\begin{array}{l}\text { No. of } \\
\text { alleles }\end{array}$ & $\begin{array}{c}\text { Allele frequencies } \\
\text { (PCR product sizes in bp) }\end{array}$ & Ho & $\mathrm{He}$ & $\begin{array}{c}\text { Hardy-Weinberg } \\
P \text {-value } \dagger\end{array}$ \\
\hline Soc 4 & $\begin{array}{l}\text { sociabilis } \\
\text { haigi }\end{array}$ & $\begin{array}{l}3 \\
5\end{array}$ & $\begin{array}{l}0.900(364), 0.050(354), 0.050(370) \\
0.421(354), 0.395(352), 0.105(358), \\
0.053(350), 0.026(356)\end{array}$ & $\begin{array}{l}0.100 \\
0.631\end{array}$ & $\begin{array}{l}0.184 \\
0.652\end{array}$ & $\begin{array}{l}0.052 \\
0.376\end{array}$ \\
\hline Soc 5 & $\begin{array}{l}\text { sociabilis } \\
\text { haigi }\end{array}$ & $\begin{array}{l}2 \\
6\end{array}$ & $\begin{array}{l}0.875(232), 0.125(250) \\
0.526(218), 0.158(240), 0.158(244), \\
0.079(238), 0.053(236), 0.026(234)\end{array}$ & $\begin{array}{l}0.219 \\
0.684\end{array}$ & $\begin{array}{l}0.218 \\
0.666\end{array}$ & $\begin{array}{l}1.000 \\
0.851\end{array}$ \\
\hline Soc 6 & $\begin{array}{l}\text { sociabilis } \\
\text { haigi }\end{array}$ & $\begin{array}{r}2 \\
11\end{array}$ & $\begin{array}{l}0.850(195), 0.150(181) \\
0.447(185), 0.158(175), 0.079 \text { (193), } \\
0.079(197), 0.053(179), 0.053(189), \\
0.026(181), 0.026(183), 0.026(187), \\
0.026(191), 0.026(195)\end{array}$ & $\begin{array}{l}0.300 \\
0.895\end{array}$ & $\begin{array}{l}0.254 \\
0.752\end{array}$ & $\begin{array}{l}1.000 \\
0.823\end{array}$ \\
\hline Soc 8 & $\begin{array}{l}\text { sociabilis } \\
\text { haigi }\end{array}$ & $\begin{array}{l}1 \\
5\end{array}$ & $\begin{array}{l}1.000(114) \\
0.289(109), 0.237(115), 0.237 \text { (117), } \\
0.132(113), 0.105(111)\end{array}$ & $\begin{array}{l}0.000 \\
0.737\end{array}$ & $\begin{array}{l}0.000 \\
0.776\end{array}$ & $\overline{0.791}$ \\
\hline
\end{tabular}

$\dagger P$-values for each locus are shown. When a sequential Bonferroni correction (Rice, 1989) is applied to these analyses ( $\mathrm{k}=32$ ), no significant deviations from Hardy-Weinberg expectations are evident.

mean size differences of $0-1$ repeat units, with the remaining loci exhibiting mean size differences of $\geq 5$ repeat units (Fig. 2). Although this distribution was not significantly different from normal (Kolmogorov-Smirnov $d=0.328,0.050<P<0.080)$, visual inspection of Fig. 2 suggests that patterns of mean size difference among alleles varied markedly among the two study populations.

For C. sociabilis, all loci with mean allele size differences of greater than four repeat units (Fig. 2) had been isolated from this species; this association between mean allele size difference and species of origin was significant (Fisher's Exact Test, two-tailed $P<0.040)$. In contrast, comparable mean differences in allele size in $C$. haigi were not significantly associated with species of origin (Fisher's Exact Test, two-tailed $P>0.050)$. Thus, in the study population of C. sociabilis, variable loci isolated from $C$. haigi were characterized by alleles that differed in size by only one or two repeat units, whereas variable loci isolated from C. sociabilis were characterized by alleles that, on average, differed in size by four or more repeat units.

\section{Allele frequency distributions}

Histograms of allele frequencies (all loci combined) differed markedly between the study populations. The distribution of allele frequencies for $C$. haigi was
L-shaped, with greater than $60 \%$ of the 112 alleles detected occurring at frequencies of $\leq 0.10$ (Fig. 3). Based on the criteria established by Luikart et al. (1998), this distribution suggests that the study population of $C$. haigi has not been subject to a recent bottleneck event. In contrast, the distribution of allele frequencies for $C$. sociabilis was much more bimodal; while roughly one-third of the 24 alleles detected occurred at frequencies of $\leq 0.10,42 \%$ of these alleles occurred at frequencies of $>0.90$ (Fig. 3). This distribution does not strictly conform to the criteria for detecting bottlenecks established by Luikart et al. (1998) in that alleles of intermediate frequencies $(0.11-0.90)$ are underrepresented. Nevertheless, the distribution of allele frequencies in the study population of $C$. sociabilis is clearly shifted toward a smaller number of more abundant alleles, as expected in populations that have experienced a bottleneck.

Estimates of $M$, the mean ratio of number of alleles to range of allele sizes (measured as number of repeat units), differed markedly between the study populations. For the seven loci that were variable in both study populations, $M$ for $C$. sociabilis was 0.48 ; in contrast, $M$ for $C$. haigi was 0.81 . Garza \& Williamson (2001) assert that, for data sets based on $\geq 7$ loci, values of $M \leq 0.68$ are indicative of a recent population bottleneck. Use of this criterion indicates that whereas the study population of $C$. sociabilis has experienced a 

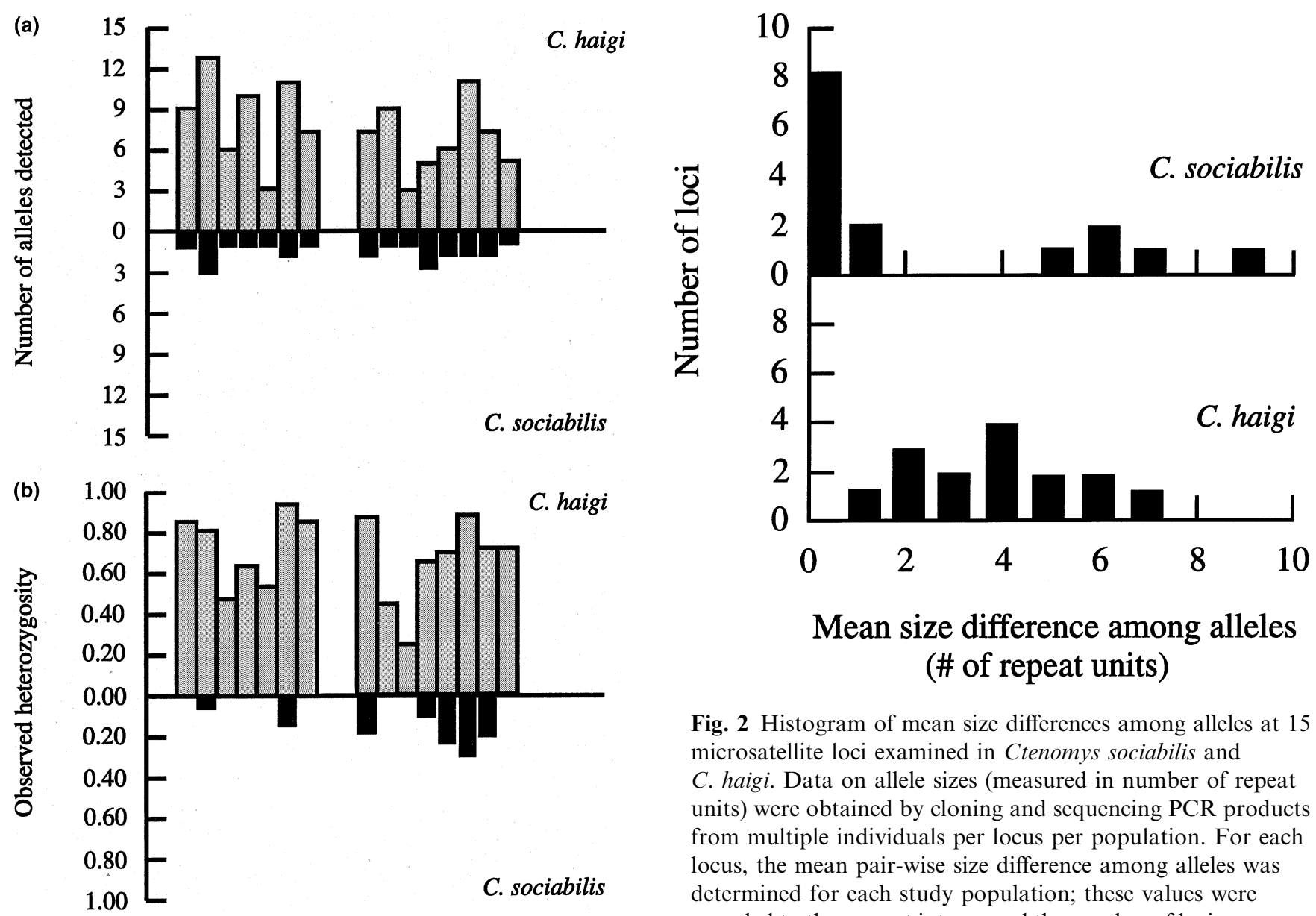

Fig. 1 Observed (a) number of alleles and (b) heterozygosity at 15 microsatellite loci from tuco-tucos. In both panels, data from Ctenomys haigi (grey bars) are presented above the horizontal axis; data from the homologous loci in $C$. sociabilis (black bars) are presented below this axis. The first seven loci depicted were isolated from $C$. haigi; a total of 35 adults per population were screened for variability at these loci. The remaining eight loci were isolated from C. sociabilis; a total of 20 adults per population were screened at these loci.

recent bottleneck event, the study population of $C$. haigi has not. Thus, both graphical analyses of allele frequency distributions and calculations of $M$ suggest that $C$. sociabilis has been more subject to historical reductions in population size than has $C$. haigi.

\section{Discussion}

Levels of microsatellite variability differed markedly among the study populations. At all loci, both the number of alleles detected and the observed heterozygosity were greater in the solitary $C$. haigi than in the group-living $C$. sociabilis (Fig. 1). This tendency was evident regardless of the species from which repeat regions had been isolated. In addition to these differ-

Fig. 2 Histogram of mean size differences among alleles at 15 microsatellite loci examined in Ctenomys sociabilis and $C$. haigi. Data on allele sizes (measured in number of repeat units) were obtained by cloning and sequencing PCR products from multiple individuals per locus per population. For each locus, the mean pair-wise size difference among alleles was determined for each study population; these values were rounded to the nearest integer and the number of loci per mean allele size was summed.

ences in variability, the study populations exhibited pronounced differences in patterns of allele size variation. In $C$. haigi, mean differences in allele size were normally distributed (Fig. 2), while in C. sociabilis, mean differences in allele size were nearly bimodal in distribution (Fig. 2). Mean size differences among alleles were not related to species of origin in C. haigi; in contrast, in $C$. sociabilis, such differences were significantly associated with the species from which microsatellites had been isolated. The distribution of allele frequencies also differed among the study populations, with allele frequencies for $C$. sociabilis clearly shifted toward the presence of a limited number of very common alleles (Fig. 3). Collectively, these data suggest intriguing differences in the processes underlying the maintenance of microsatellite variation in the two study populations.

Multiple factors may have contributed to the differences in microsatellite variability evident between the study populations, including differences in current behaviour and demography, population history and molecular properties.

(C) The Genetics Society of Great Britain, Heredity, 86, 628-637. 


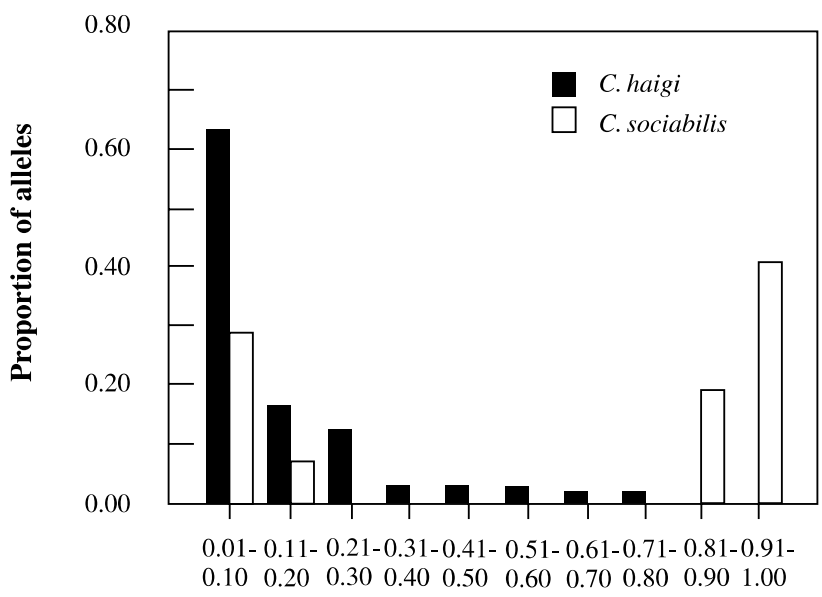

Allele frequency

Fig. 3 Comparison of allele frequency distributions in the two study populations. The proportion of all alleles detected (Ctenomys haigi, $n=112 ;$ C. sociabilis, $n=24$ ) falling within each allele frequency class is shown for each population. Interpretations of these distributions based on Luikart et al. (1998) indicate that the allele frequency distribution for C. haigi is consistent with that expected for populations that have not experienced a recent reduction in size; in contrast, the distribution of $C$. sociabilis more closely resembles those from populations known to have experienced recent bottleneck events.

\section{Differences in current behaviour and demography}

As already noted, $C$. haigi and $C$. sociabilis exhibit a number of behavioural and demographic differences that are expected to impact patterns of population-level genetic variation in these species. The most conspicuous of these differences is the formation of social groups by C. sociabilis. Group living in this species arises due to natal philopatry by females (Lacey et al., 1997; Lacey, 2000), which leads to the spatial aggregation of individuals that share alleles due to recent common ancestry. The presence of distinct social units is typically expected to favour increased genetic variation within local populations due to the maintenance of genetic differences among groups (Dobson et al., 1998). In C. sociabilis, however, rapid turnover of groups and recolonization of burrow systems from within the population, combined with limited migration between populations (Lacey, unpublished data), suggest that all members of a local population share a considerable portion of their genetic material due to shared ancestry.

In contrast, burrow systems of $C$. haigi are inhabited by only a single adult (Lacey et al., 1998), with no tendency for related individuals (e.g. females and offspring) to occupy adjacent burrow systems (Lacey, unpublished data). These behavioural differences, com- bined with the tendency for $C$. haigi burrows to be recolonized by individuals from outside the study population (Lacey, unpublished data), imply that variation within local populations of this species should be greater than that within local populations of $C$. sociabilis. The microsatellite data reported here are consistent with this expectation, suggesting that current behavioural and demographic variables contribute to the differences in genetic variability evident among the study populations.

\section{Differences in population history}

Historical differences between the study populations may also contribute to the patterns of microsatellite variation reported here. In particular, interspecific differences in patterns of population formation and the frequency of population bottlenecks may play a role in generating the observed differences in genetic variability. Populations that are founded by a small number of individuals will have relatively low levels of initial variability (i.e. a strong founder effect); this limited variability may be perpetuated due to subsequent low levels of gene flow and consistently small effective population size (Hartl \& Clark, 1997). Populations that are subject to pronounced bottlenecks will undergo marked reductions in variability, the effects of which may remain evident in current surveys of genetic variation (Avise, 1994).

Although the histories of the study populations are not known, the current demographic differences between these populations suggest that they are likely to have experienced different historical rates of gene flow, drift, and extinction/recolonization. In addition, the distinct allele size and allele frequency distributions reported here are consistent with differences in the frequency of population bottlenecks. The distribution of mean allele size differences in C. sociabilis, in particular the presence at several loci of a limited number of alleles of very different sizes (Fig. 2), is suggestive of one or more historical bottlenecks in which only a few alleles of quite different sizes were preserved (e.g. Garza \& Williamson, in press). Further, whereas the distribution of allele frequencies for $C$. haigi is consistent with that expected for non-bottlenecked populations, the distribution of allele frequencies for $C$. sociabilis is more consistent with patterns observed in populations thought to have experienced a recent bottleneck event (Luikart et al., 1998). Finally, estimated $M$ for C. sociabilis falls within the range of values thought to reflect recently bottlenecked populations, whereas $M$ for $C$. haigi does not. If these interpretations of the allele size and allele frequency data are correct, they suggest that the study population of $C$. sociabilis has been more subject to past reduction(s) in population size than has 
the study population of $C$. haigi. Thus population history may contribute not only to the observed difference in levels of microsatellite variability, but also to the patterns of allelic variation underlying this difference in variability.

\section{Differences in molecular properties}

In addition to the population-level parameters discussed above, several structural attributes of microsatellite markers may contribute to the observed differences in patterns of genetic variation. In the present study, multiple steps were undertaken to reduce the probability that the genetic data were influenced by such factors. First, only microsatellites characterized by the same repeat motif in both study populations were screened (Table 1; Lacey et al., 1999); by controlling for differences in repeat motif and by restricting comparisons almost exclusively to dinucleotide repeats, motif-related biases in variability (e.g. Pépin et al., 1995; Chakraborty et al., 1997) should have been minimized. Second, none of the loci included in this study were screened to assess variability prior to the generation of the data summarized in Table 2. As a result, measures of variability at these loci should not have been subject to ascertainment biases associated with the selection of a particular subset of loci for analysis (e.g. the most variable loci in one species; Ellegren et al., 1995). Indeed, because loci isolated from both $C$. sociabilis and $C$. haigi were used, the consistently greater variability detected for $C$. haigi cannot be attributed to structural or other properties of microsatellites that differ between source and nonsource species for these markers.

With regard to the data generated, observed heterozygosities at variable loci in both study populations were consistent with Hardy-Weinberg expectations (Table 2), providing no evidence that these data were influenced by the presence of null alleles (Pemberton et al., 1995). Although Hardy-Weinberg calculations could not be used to assess the potential for null alleles at the eight loci that were monomorphic for $C$. sociabilis, the marked similarity of flanking region sequences across the study species suggests that non-amplification of alleles due to primer-template mismatch was unlikely. It also seems unlikely that non-amplification of alleles would result in monomorphism at eight apparently unlinked loci in $C$. sociabilis (Table 2), including three loci isolated from that species. Thus, non-amplification of alleles does not appear to provide a comprehensive explanation for the consistently greater microsatellite variability evident in $C$. haigi.

The one aspect of microsatellite behaviour that did appear to vary between the study populations was the distribution of allele sizes at a locus. As suggested by
Fig. 2, whereas mean allele size differences for $C$. haigi were normally distributed, mean size differences for C. sociabilis appeared to be almost bimodal in distribution, with some loci characterized by very pronounced differences in allele size. Although this association between allele size difference and species of origin at first appears suggestive of some form of ascertainment bias, the absence of any other interspecific biases in allele size, structure, or behaviour provides no obvious mechanism for generating this relationship. Instead, given the limited number of variable loci detected in C. sociabilis, it is possible that this relationship is simply a stochastic consequence of the microsatellite regions chosen for analysis.

\section{Conclusions}

Collectively, these analyses suggest that the striking differences in variability evident between the study populations reflect population-level, rather than molecular-level processes. Specifically, the absence of detectable biases in microsatellite structure, combined with the greater polymorphism and heterozygosity evident in C. haigi across all loci, suggests that variability in the study populations is influenced primarily by current demography and population history. In particular, the distributions of allele size differences and allele frequencies in $C$. sociabilis suggest that this population has been more subject to historical reductions in population size than has the study population of C. haigi. Thus, investigation of the structure and behaviour of the microsatellite markers used in this study not only mitigates concerns regarding potentially confounding molecular-level phenomena, but also provides intriguing suggestions as to the nature of the population-level forces that have contributed to markedly different levels of variability in the study populations. Future studies of these animals will explore the interplay of these factors in greater detail by using the microsatellite markers characterized here to assess patterns of among-population variation in each study species.

\section{Acknowledgements}

I am indebted to $\mathrm{K}$. Lindstrom for her help in isolating microsatellite markers from $C$. sociabilis. T. Hambuch, M. Matocq, N. Gordon, and U. Hager are also thanked for their assistance with the laboratory work. T. Hambuch, E. Lessa, M. Matocq, J. Patton, M. Smith, and two anonymous referees provided valuable commentary on earlier versions of the manuscript. Financial support for the project was provided by the Museum of Vertebrate Zoology, the Hellman Family Junior Faculty 
Fund, the Committee on Research at the University of California, Berkeley, and the National Science Foundation (no. DEB-9704462).

\section{References}

AVISE, J. C. 1994. Molecular Markers, Natural History, and Evolution. Chapman \& Hall, New York.

CHAKRABORTY, R., KIMMEL, M., STIVERS, D. N., DAVISON, L. J. $E T A L$. 1997. Relative mutation rates at di-, tri-, and tetranucleotide microsatellite loci. Proc. Natl. Acad. Sci. U.S.A., 94, 1041-1046.

DOBSON, F. S., CHESSER, R. K., HOOGLAND, J. L., SUGG, D. W. ET AL. 1998. Breeding groups and gene dynamics in a socially structured population of prairie dogs. J. Mammal., 79, 671680.

Ellegren, H., PRIMMER, C. R. AND SHELDON, B. C. 1995. Microsatellite 'evolution': directionality or bias? Nature Genet., 11, 360-362.

ESTOUP, A., TAILliEZ, C., CORNUET, J.-M. AND SOLIGNAC, M. 1995. Size homoplasy and mutational processes of interrupted microsatellites in two bee species, Apis mellifera and Bombus terrestris (Apidae). Mol. Biol. Evol., 12, 1074-1084.

GARZA, J. C. AND Williamson, E. G., 2001. Detection of reduction in population size using data from microsatellite loci. Mol. Ecol., 10, 305-318.

HARTL, D. L. AND ClARK, A. G. 1997. Principles of Population Genetics, 3rd edn. Sinauer Associates, Sunderland, MA.

ISHIBASHI, Y., SAITOH, T., ABE, S. AND YOSHIDA, M. C. 1996. Null microsatellite alleles due to nucleotide sequence variation in the grey-sided vole, Clethrionomys rufocanus. Mol. Ecol., 5, 589-591.

LACEY, E. A. 2000. Spatial and social systems of subterranean rodents. In: Lacey, E. A., Patton, J. L. and Cameron, G. N. (eds) Life Underground. The Biology of Subterranean Rodents, pp. 257-296. University of Chicago Press, Chicago.

LACEY, E. A., BRAUDE, S. H. AND WIECZOREK, J. R. 1997. Burrow sharing by colonial tuco-tucos (Ctenomys sociabilis). J. Mammal., 78, 556-562.

LACEY, E. A., BRAUde, S. H. AND WIECZOREK, J. R. 1998. Solitary burrow use by adult Patagonian tuco-tucos (Ctenomys haigi). J. Mammal., 79, 986-991.

LACEY, E. A., MALDONADO, J. E., CLABAUGH, J. P. AND MATOCQ, M. D. 1999. Interspecific variation in microsatellites isolated from tuco-tucos (Rodentia: Ctenomyidae). Mol. Ecol., 8, 1754-1756.

LESSA, E. P. AND COOK, J. A. 1998. The molecular phylogenetics of tuco-tucos (genus Ctenomys, Rodentia: Octodontidae) suggests an early burst of speciation. Mol. Phylogenet. Evol., 9, 88-99.

LUIKART, G., ALLENDORF, F. W., CORNUET, J.-M. AND SHERWIN, W. B. 1998. Distortion of allele frequency distributions provides a test for recent population bottlenecks. J. Hered., 89, 238-247.

PEMBERTON, J. M., SLATE, J., BANCROFT, D. R. AND BARRETT, J. A. 1995. Nonamplifying alleles at microsatellite loci: a caution for parentage and population studies. Mol. Ecol., 4, 249-252.

PÉPIN, L., AMIGUES, Y., LéPINGLE, A., BERTHIER, J.-L. ET AL. 1995. Sequence conservation of microsatellites between Bos taurus (cattle), Capra hircus (goat), and related species. Examples of use in parentage testing and phylogeny analysis. Heredity, 74, 53-61.

RICE, W. R. 1989. Analyzing tables of statistical tests. Evolution, 43, 223-225.

RICHARDSON, C. C. 1965. Phosphorylation of nucleic acid by an enzyme from T4 bacteriophage-infected Escherichia coli. Proc. Natl. Acad. Sci. U.S.A., 54, 158-165.

SAMBROOK, J., FRITSCH, E. F. AND MANIATIS, T. 1989. Molecular Cloning: A Laboratory Manual, Vols 1-3. Cold Spring Harbor Press, Cold Spring Harbor, NY.

SCHNEIDER, S., ROESSLI, D. AND EXCOFFIER, L. 1995. ARLEQUIN, Version 1.1: a software for population genetic data analysis. Genetics and Biometry Laboratory, University of Geneva, Switzerland.

SEUTIN, G., WHITE, B. N. AND BOAG, P. T. 1991. Preservation of avian blood and tissue samples for DNA analysis. Can. J. Zoology, 69, 82-90.

VAN TREUREN, R., KUITTINEN, H., KÄRKKÄINEN, K., BAENAGONZALEZ, E. ET AL. 1997. Evolution of microsatellites in Arabis petraea and Arabis lyrata, outcrossing relatives of Arabidopsis thaliana. Mol. Biol. Evol., 14, 220-229.

WEIR, B. S. 1990. Genetic Data Analysis. Sinauer Associates, Sunderland, MA.

woods, C. A. 1993. Suborder Hystricognathi. In: Wilson, D. E. and Reeder, D. M. (eds) Mammal Species of the World: A Taxonomic and Geographic Reference, pp. 771-806. 2nd edn. Smithsonian Institution Press, Washington, DC. 